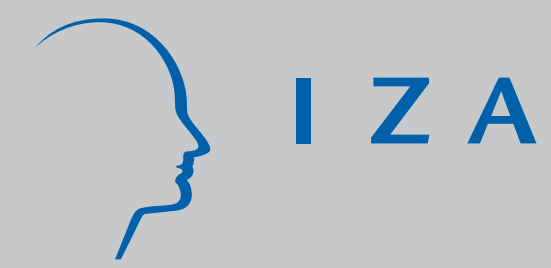

IZA DP No. 5389

Self Selection Does Not Increase Other-Regarding

Preferences among Adult Laboratory Subjects, but

Student Subjects May Be More Self-Regarding than Adults

Jon Anderson

Karsten Maurer

Stephen V. Burks

Daniele Nosenzo

Jeffrey Carpenter

Lorenz Götte

Ruth Potter

Kim Rocha

Aldo Rustichini

December 2010 


\title{
Self Selection Does Not Increase Other-Regarding Preferences among Adult Laboratory Subjects, but Student Subjects May Be More Self-Regarding than Adults
}

\author{
Jon Anderson \\ University of Minnesota, Morris
}

\author{
Stephen V. Burks \\ University of Minnesota, Morris \\ and IZA
}
Jeffrey Carpenter
Middlebury College, McGill University and IZA

\author{
Lorenz Götte \\ University of Lausanne \\ and IZA
}

Karsten Maurer
lowa State University

Daniele Nosenzo

University of Nottingham

\author{
Ruth Potter \\ University of Minnesota, Morris
}

Kim Rocha

University of Minnesota, Morris
Aldo Rustichini

University of Minnesota, Twin Cities

and Cambridge University

Discussion Paper No. 5389

December 2010

\author{
IZA \\ P.O. Box 7240 \\ 53072 Bonn \\ Germany \\ Phone: +49-228-3894-0 \\ Fax: +49-228-3894-180 \\ E-mail: iza@iza.org
}

Any opinions expressed here are those of the author(s) and not those of IZA. Research published in this series may include views on policy, but the institute itself takes no institutional policy positions.

The Institute for the Study of Labor (IZA) in Bonn is a local and virtual international research center and a place of communication between science, politics and business. IZA is an independent nonprofit organization supported by Deutsche Post Foundation. The center is associated with the University of Bonn and offers a stimulating research environment through its international network, workshops and conferences, data service, project support, research visits and doctoral program. IZA engages in (i) original and internationally competitive research in all fields of labor economics, (ii) development of policy concepts, and (iii) dissemination of research results and concepts to the interested public.

IZA Discussion Papers often represent preliminary work and are circulated to encourage discussion. Citation of such a paper should account for its provisional character. A revised version may be available directly from the author. 


\section{ABSTRACT \\ Self Selection Does Not Increase Other-Regarding Preferences among Adult Laboratory Subjects, but Student Subjects May Be More Self-Regarding than Adults ${ }^{*}$}

We use a sequential prisoner's dilemma game to measure the other-regarding behavior in samples from three related populations in the upper Midwest of the United States: 100 college students, 94 non-student adults from the community surrounding the college and 1,069 adult trainee truckers in a residential training program. Both of the first two groups were recruited according to procedures commonly used in experimental economics (i.e., via e-mail and bulletin-board advertisements) and therefore subjects self-selected into the experiment. Because the structure of their training program reduced the opportunity cost of participating dramatically, $91 \%$ of the solicited trainees participated in the third group, so there was little scope for self-selection in this sample. We find no differences in the elicited other-regarding preferences between the self-selected adults and the adult trainees, suggesting that selection into this type of experiment is unlikely to bias inferences with respect to non-student adult subjects. We also test (and reject) the more specific hypothesis that approval-seeking subjects are the ones most likely to select into experiments. At the same time, we find a large difference between the self-selected students and the self-selected adults from the surrounding community: the students appear considerably less pro-social. Regression results controlling for demographic factors confirm these basic findings.

JEL Classification: C90, D03

Keywords: methodology, selection bias, laboratory experiment, field experiment, other-regarding behavior, social preferences, truckload, trucker

Corresponding author:

Stephen V. Burks

Division of Social Science

University of Minnesota Morris

600 East 4th Street

Morris, Minnesota 56267

USA

E-mail: svburks@morris.umn.edu

\footnotetext{
* The Truckers and Turnover Project acknowledges financial and in-kind support from the cooperating firm, and financial support from the MacArthur Foundation's Research Network on the Nature and Origin of Norms and Preferences, the Sloan Foundation's Industry Studies Program, the Trucking Industry Program at Georgia Institute of Technology, the University of Nottingham, and the University of Minnesota, Morris. Götte acknowledges support from the Federal Reserve Bank of Boston, and Nosenzo from the Leverhulme Foundation (ECF/2010/0636). The authors thank Simon Gächter, John Galbraith, and Herbert Gintis for helpful comments. The views expressed are those of the authors, and do not necessarily reflect those of the supporting entities.
} 
IZA Discussion Paper No. 5389

December 2010

\section{NON-TECHNICAL SUMMARY}

There is a significant amount of laboratory data showing that in many experiments a considerable fraction of subjects will give up money to reward or punish others when there is no self-interested reason, such a maintaining a positive reputation, to do so. Experimental economists have been concerned that the frequency of this behavior among typical subjects, college students, might be misleadingly high, because those most likely to be other-regarding might also be most likely to volunteer as experimental subjects, and also because college students might be more idealistic and other-regarding than typical non-student adults. We study the frequency of a specific other-regarding behavior - costly cooperation - among three samples: the usual self-selected students, self-selected adults from the same town as the college, and a large group of trainee truckers learning their new job. We find that selfselection does not change the frequency of costly cooperation among our adult subjects, and also that our student subjects actually appear to be less, not more, other-regarding than our adult subjects. This suggests that self-selected student subjects may indeed be giving us the wrong impression, but in the opposite direction: they are less likely overall to engage in costly cooperation. 


\section{Introduction}

A considerable body of evidence has now accumulated from economic experiments that many individuals exhibit "other-regarding preferences:" not only do they care about their personal material payoffs from social and economic interactions, but they also care about the payoffs of other agents with whom they interact. The designs of such experiments control, at least to a good first approximation, for potentially confounding reasons - such as repeated interactions or reputation effects - that could lead to what appears to be other-regarding behavior but is really sophisticated self-interest. For example, in the context of voluntary cooperation games only about a third of the participants in experiments typically behave in accordance with own-payoff maximization. The majority of individuals seems instead motivated by otherregarding considerations. For example, more than half of the participants are found to be "conditionally cooperative" - they are willing to forgo material gain and cooperate if others cooperate as well (see, e.g., (Fischbacher et al., 2001; Herrmann and Thoni, 2009; Kocher et al., 2008)). Analogous evidence of the importance of other-regarding preferences has been documented by experimental studies using dictator games, bargaining games, trust games and gift-exchange games (for a review see, e.g., (Camerer, 2003; Fehr and Schmidt, 2006)).

However, most of the economic experiments providing evidence for the importance of other-regarding motives have been conducted using samples of undergraduate students who selfselected into the experimental studies as participants. Generalizing from findings based on selfselected student samples to what members of the broader population might do in such laboratory experiments could be problematic for two reasons. First, experimental studies relying on selfselected samples may overestimate the importance of other-regarding preferences if the process by which participants self-select into experiments is correlated with their preferences. For example, as suggested by Levitt and List (2007, p. 166) “... volunteers ... who have social preferences or who readily cooperate with the experimenter and seek social approval might be those who are most likely to participate in the experiment." If this were the case, the pervasiveness of social and other-regarding behaviors documented in economic experiments could substantially reflect the endogenous process by which the experimental participants were selected rather than the underlying propensities of the population. Second, students clearly differ in important ways from the general population (e.g. in terms of age, education, social class and 
experience with markets and economic environments), and in principle it is possible that they may also differ in the strength of their other-regarding concerns.

In this paper we address these concerns by examining how other-regarding preferences measured in a laboratory experiment vary across three different samples of experimental subjects. One sample consists of undergraduates students who self-select into the laboratory experiment. The two other samples consist of participants recruited among the non-student adult population. These two non-student samples differ in the procedures used to recruit participants: in one case the recruitment procedures were similar to those used for recruiting undergraduates, and participants could self-select into the experiment. In the other case, the recruitment procedures allowed for very little self-selection of participants.

As described in detail in Section 2, we measure other-regarding preferences using a sequential social dilemma game in which players choose between an uncooperative action that leaves earnings unaffected, and cooperative actions that are costly for the player, but benefit their partner and increase total earnings. In the experiment decisions were elicited using the strategy method and subjects played both in the role of first-mover and in the role of second-mover. We use decisions in the role of second-mover to classify subjects in three main categories: FreeRiders, who do not display other-regarding concerns and choose the own-payoff maximizing actions, Conditional Cooperators, who behave cooperatively only if the first-mover behaves cooperatively, and Unconditional Cooperators, who behave cooperatively regardless of how the first-mover behaves. The latter two types both exhibit other-regarding concerns in the sense that they choose actions that are inconsistent with own-payoff maximization. Finally, our data also include a measure of subjects' need for social approval (the "Unlikely Virtues Scale", developed by Patrick et al., 2002), which we use to examine whether, as suggested by Levitt and List (2007), approval-seeking is positively related to decisions to self-select into experimental studies.

We report our results in Section 3. To examine whether other-regarding preferences are more widespread among self-selected participants than among non-self-selected participants we compare the distribution of cooperation types across the two samples of adult non-students, which vary on this dimension. We find that the proportions of Free Riders, Conditional Cooperators, and Unconditional Cooperators do not differ significantly between the two groups. We also do not find any difference in the need for social approval of self-selected and non-selfselected participants. To examine whether there are differences in the extent to which students 
and non-students engage in other-regarding behaviors we compare our two self-selected samples, the former composed of students and the latter of non-student adults. We find that the share of individuals exhibiting other-regarding concerns is remarkably smaller among students, even after controlling for observable differences in socio-demographic characteristics between the two subject pools.

We discuss these results and related literature in Section 4. Our finding that the impact of self-selection on measurements of other-regarding preferences is negligible is consistent with the results of two related recent studies. Cleave et al. (2010) compare a self-selected subset of student subjects in a lab setting with the larger population $(1,173$ students in an introductory microeconomics class who did an in-class experiment) from which they were drawn, and find no difference in the level of pro-social behavior. Falk et al. (2010) compare the rate of donations to an all-university charity by the $10 \%$ of students who participated in economics experiments as compared to the $90 \%$ who did not, and find no differences. The present study is distinct in three ways. We examine self-selection not among students but among non-student adults, and we simultaneously address both self-selection and the comparison of students and non-student adults using exactly the same protocol, while also accounting for the desire for social approval across our subject pools, thereby ruling out confounds and doubts that cannot be addressed by these two complementary papers.

In addition, as in two precursor studies by Carpenter et al. (2005) (using ultimatum and dictator bargaining) and Burks et al. (2009a) (using a simpler version of the present paper's protocol), and consistent with further results in Falk et al. (2010) (using a trust game), our results suggest that measurements of other-regarding preferences obtained from student samples might understate the importance of other-regarding motives. In fact, there is now a significant body of evidence suggesting that--in non-market experimental settings--students' preferences represent a lower bound of the other-regarding inclinations of the more general population in advanced industrial societies (see Section 4 below, and Henrich et al. (2010) for a review of related literature).

\section{Experimental Design and Procedures}

\subsection{Subject pools}

The data used in this paper were collected from 1261 subjects who took part in the Truckers \& Turnover Project, an extensive experimental study run in two locations over two 
years and comprised of several decision tasks and questionnaires (Burks et al., 2008). ${ }^{1}$ Participants in the experiment belonged to one of three different subsets, which differ in whether subjects were undergraduate students or not, and/or in the procedures used to recruit them (see Table 1: Design).

One-hundred subjects were students at the University of Minnesota, Morris (UMM). They were recruited by e-mail through the opt-out student list at UMM. An initial invitation e-mail was sent out asking for those interested in participating as paid volunteers in experiments to respond. Responders were then contacted via e-mail with information about specific session times and potential earnings, and allocated to sessions based on availability. These recruitment procedures are similar to those typically used for economic experiments. In particular, note that these participants self-selected into the experiment. We thus refer to this sample of subjects as Subset 1: Self-Selected Students.

Ninety-two subjects were recruited from the non-student population living in the vicinity of Morris, which is a town of 5,000 in a rural area. Recruitment was done by placing posters on business bulletin boards in Morris. Posters contained information about the experiment, potential earnings, and possible session times, and had pre-paid mail-back postcards for those interested in participating. Responders were then contacted by telephone to arrange session allocation. Thus, the recruitment procedures used for this subject pool were similar to those used for students. In particular, these ninety-two subjects also self-selected into the experiment, as the subjects in the student subset did. We thus refer to this sample as Subset 2: Self-Selected Non-Students.

The remaining one-thousand and sixty-nine subjects were also recruited from a population of subjects who were not enrolled in university or college. These subjects were trainee truck drivers at a driver training school in the U.S. Midwest operated by a large trucking firm which provides basic training to its new-to-the-industry employees. The researchers had the cooperation of the trucking firm that runs the school, and the data collection was designed to make the opportunity cost of participation particularly low. At the beginning of the class day, one of the authors (Burks) approached the trainees and conducted an informed consent process, in which he explained the goals and procedures of the experimental study to potential subjects. While trainees were informed that participation in the study was voluntary and that those who wished

\footnotetext{
${ }^{1}$ The full set of activities took four and a half hours, including informed consent and a pair of two-hour-long activity blocks with a quarter hour break in between.
} 
not to participate were excused, the relatively low opportunity cost of participating and the credible guarantee of confidentiality from the University ${ }^{2}$ resulted in a very high participation rate: $91 \%$ of those offered the opportunity chose to join the study. ${ }^{3}$ Thus, there is very little selfselection into the experiment by this group of subjects. We refer to the trainees sample as Subset 3: Non-Self-Selected Non-Students.

Table 1: Design

\begin{tabular}{c|cc}
\hline \hline & Students & Non-Students \\
\hline Self-Selected & 100 & 87 \\
Non Self-Selected & N/A & 1,044 \\
\hline \hline
\end{tabular}

Note: numbers of subjects with complete questionnaire data. These restricted samples will be used for the data analysis in Section 3.

All subjects were exposed to the same experimental protocol (see (Burks et al., 2008) for more details). At the beginning of each session subjects were guided through a consent form that explained the conditions for participation in the study. The experiment was set up as two twohour-long blocks that subjects spent doing tasks with the researchers, either on computers or with paper and pencil, with a short break in between. ${ }^{4}$ The part of the experimental design used in the current study is described in detail in the next sub-section. At the beginning of each two-hourlong block subjects received a fixed payment of $\$ 10$ for their participation, and could earn additional money in the course of the experiment depending on their performance. ${ }^{5}$ Sessions were run with groups ranging from 20 to 40 subjects at a time. Four sessions were conducted with Subset 1, Self-Selected Students, three sessions with Subset 2, Self-Selected Non-Students, and forty-six sessions with Subset 3, Non-Self-Selected Non-Students.

\footnotetext{
${ }^{2}$ Specifically, subjects were informed that the data was going to the University and not the firm (their new employer), and the role of the University's Institutional Review Board (IRB) in enforcing the promise of individual confidentiality was explained.

${ }^{3}$ With the cooperation of the training school, the study was run on Saturdays that came in the middle of a two-week residential basic training program. Lunch was provided and the buses to and from the trainee's lodgings arrived at an early hour and left at the end of the afternoon. Only a half day of training activity was scheduled, so trainees were split into two groups and in the morning one did training while the other took part in the study, with the reverse in the afternoon. Those not participating in the study with their group did not have extra training available and had to spend the time in a break room.

${ }^{4}$ The computerized tasks were programmed and implemented with the software z-Tree (Fischbacher, 2007).

${ }^{5}$ The fixed payments were doubled for Self-Selected Non-Students because on average they faced relatively higher opportunity costs to participation, since they had to come to campus from the surrounding town.
} 


\subsection{Experimental measurements}

Our measurement of subjects' other-regarding preferences is based on the decisions they made in the following social dilemma game, a sequential version of the prisoner's dilemma. At the outset of the "Two-Person Sending Task" two players, Person 1 and Person 2 are each allocated $\$ 5$. Person 1 moves first and chooses an amount $s_{1} \in\{\$ 0, \$ 5\}$ to send to Person 2 . Person 2 learns Person 1's decision and then chooses an amount $s_{2} \in\{\$ 0, \$ 1, \$ 2, \$ 3, \$ 4, \$ 5\}$ to send back to Person 1. Any amount sent by either player is doubled by the experimenter, and this is common knowledge. After Person 2's decision, the game ends, and payoffs are computed as:

$$
\pi_{i}=\$ 5-s_{i}+2 * s_{j}
$$

for $i, j \in\{1,2\}$, and $i \neq j$.

In the experiment subjects played the game exactly once, and were asked to make decisions in both roles knowing that the final assignment to roles would be randomly determined at the end of the experiment. On a first screen subjects were asked to make a decision in the role of Person 1 , and on a second screen a decision in the role of Person $2 .^{6}$ Person 2's decisions were elicited using the strategy method, i.e. subjects had to specify the amount they intended to transfer to Person 1 both for the case where Person 1 had sent $\$ 0$ and for the case where Person 1 had sent $\$ 5$. Thus, subjects in the experiment were asked to make three decisions in total: one decision in the role of Person 1 and two decisions in the role of Person 2. Once all decisions had been made, subjects were anonymously and randomly matched with another participant in the room, were randomly assigned a role, and were shown their payoffs according to the decisions they had made in that role. On average, subjects earned $\$ 8.32$ from the social dilemma game, with a minimum of $\$ 0$ and a maximum of $\$ 16$.

The sequential social dilemma game described above was the first task that subjects performed in the experiment. Of the subsequent tasks that subjects had to complete one is of particular interest for the purposes of this study. After their choices in the social dilemma game, subjects were asked to fill out the brief form of the Multidimensional Personality Questionnaire (MPQ) developed by Patrick et al. (2002). This is a personality profile test consisting of eleven different scales representing primary trait dimensions, and one 13-item scale (the "Unlikely

\footnotetext{
${ }^{6}$ Before each decision screen subjects were also asked to predict the behavior of the other participants in the room, and received additional earnings for correct answers, which is why the highest earnings were $\$ 16.00$ (see Burks $e t$ al. (2008)).
} 
Virtues Scale") which provides a stand-alone index of social desirability. ${ }^{7}$ Scores in the version of the Unlikely Virtues Scale administered to subjects can range from 13 to 52 and high scores result when subjects over-report uncommon "good behaviors" (e.g. they answer positively to questions such as "Never in my whole life have I taken advantage of anyone") and under-report common "bad behaviors" (e.g. they answer negatively to questions such as "I have sometimes felt slightly hesitant about helping someone who asked me to"). In our sample we find that the intercorrelations of the 13 items of the scale exceed the standard threshold (Chronbach's alpha is 0.73) and so we conclude that our implementation has resulted in capturing the desired latent trait. We will use the Unlikely Virtues Scale to examine whether there is any relation between approval-seeking (in the form of more socially desirable responding) and decisions to take part into economic experiments.

As part of the experimental design, subjects completed a questionnaire collecting basic socio-demographic information. Table 2 presents a summary of subjects' socio-demographic characteristics disaggregated by subject pool. Although there is a fair amount of overlap in most of the socio-demographic dimensions, there are also important differences across the three subject pools. In terms of age, Subset 1, Self-Selected Students, are on average younger than both non-student groups, and Subset 3, Non-Self-Selected Non-Students, are younger than Subset 2, Self-Selected Non-Students. The three subject pools also differ in terms of gender composition: both non-student groups are predominantly composed of male subjects, while the majority of students are female. In terms of years spent in education, Subset 3, Non-SelfSelected Non-Students are less educated than both Subset 1, Self-Selected Students, and Subset 2, Self-Selected Non-Students. Other notable differences across groups are in terms of their racial composition (with Subset 2, Self-Selected Non-Students, being less likely to be classified as "Non-White or Hispanic"), and in terms of disposable income (Subset 1, Self-Selected Students, have higher incomes than both other groups, and Subset 2, Self-Selected Non-Students, have higher incomes than Subset 3, Non-Self-Selected Non-Students). In the data analysis presented in the next section we will use regression analysis to account for these differences across subject pools.

\footnotetext{
${ }^{7}$ The Unlikely Virtues Scale developed by (Patrick et al., 2002), actually consists of 14 items. Due to a programming error, one item was not included in the questionnaire administered to participants in the experiment.
} 
Table 2: Summary Demographic Statistics

\begin{tabular}{|c|c|c|c|}
\hline & $\begin{array}{c}\text { Subset } 1 \\
\text { Self-Selected } \\
\text { Students } \\
(\mathrm{n}=100)\end{array}$ & $\begin{array}{c}\text { Subset } 2 \\
\text { Self-Selected } \\
\text { Non-Students } \\
(\mathrm{n}=87)\end{array}$ & $\begin{array}{c}\text { Subset } 3 \\
\text { Non-Self-Selected } \\
\text { Non-Students } \\
(\mathrm{n}=1044)\end{array}$ \\
\hline Age, mean (min. - max.) & $20.9(18-41)$ & $42.1(21-66)$ & $37.2(21-69)$ \\
\hline Female (\%) & 0.61 & 0.41 & 0.10 \\
\hline Non - White or Hispanic (\%) & 0.23 & 0.05 & 0.19 \\
\hline Number of Siblings, mean (s.d.) & $2.0(1.2)$ & $2.9(1.6)$ & $2.9(2.0)$ \\
\hline Years of Education Completed, mean (s.d.) & $14.2(1.1)$ & $14.3(2.0)$ & $13.0(1.7)$ \\
\hline \multicolumn{4}{|l|}{ Own Marital Status (\%) } \\
\hline Married or in marriage-type relationship & 0.03 & 0.66 & 0.48 \\
\hline Single/Separated/Divorced/Widowed & 0.97 & 0.34 & 0.52 \\
\hline \multicolumn{4}{|l|}{ Marital Status of Parents (\%) } \\
\hline Married or in marriage-type relationship & 0.88 & 0.83 & 0.67 \\
\hline Single/Separated/Divorced/Widowed & 0.12 & 0.17 & 0.33 \\
\hline \multicolumn{4}{|l|}{ Income Category (\%) } \\
\hline$\$ 0-\$ 10,000$ & 0.07 & 0.01 & 0.39 \\
\hline$\$ 10,000-\$ 20,000$ & 0.00 & 0.05 & 0.16 \\
\hline$\$ 20,000-\$ 30,000$ & 0.08 & 0.11 & 0.15 \\
\hline$\$ 30,000-\$ 40,000$ & 0.00 & 0.21 & 0.11 \\
\hline$\$ 40,000-\$ 50,000$ & 0.18 & 0.13 & 0.07 \\
\hline$\$ 50,000-\$ 60,000$ & 0.00 & 0.11 & 0.05 \\
\hline$\$ 60,000-\$ 70,000$ & 0.21 & 0.07 & 0.03 \\
\hline$\$ 70,000+$ & 0.46 & 0.31 & 0.04 \\
\hline
\end{tabular}

The variable "Years of Education Completed" was derived by asking subjects to indicate the highest level of education they had completed at the time of the experiment. For Students we refine this measure by distinguishing between freshmen, sophomores, juniors and seniors using the self-reported number of accumulated college credits at the time of the experiment. For Students the variable "Income Category" was derived from the question "Which range best fits the annual income of your parents (step-parents)?". For non-students "Income Category" was constructed by combining their answers to the questions: "Not counting your earnings, which range best fits the annual income you and your household have from other sources?" and "Which range best describes the annual earnings you would normally expect from your usual jobs?". For Non-Self-Selected Non-Students, which were undertaking full-time training and were thus unemployed at the time of the experiment, only answers to the first question was used. Other variables are self-explanatory. The variable Number of Siblings was coded as missing for the 27 subjects who reported having more than 10 siblings.

\section{Results}

We are mainly interested in addressing the following questions: 1) Is the pervasiveness of other-regarding motives overstated by measurements based on samples of self-selected participants?; and 2) Are other-regarding preferences as widespread among student samples as among non-student samples? To examine these questions, we start by classifying subjects in different "preference types" based on the cooperativeness of their choices in the role of secondmover in the social dilemma game described above. We then compare how the distributions of these types vary across the three subject pools. To address the first question, we compare Subsets 2 and 3 , 
the two samples of non-student adults, which differ in whether subjects self-selected into the study or not. To address the second question we compare Subsets 1 and 2, both of which were selfselected, but which differ in being drawn from student versus non-student adult populations. ${ }^{8}$ The section concludes by examining the differences across subsets in subjects' need for social approval as measured by the Unlikely Virtues Scale.

\subsection{Other-regarding preferences across subject pools}

We measure subjects' other-regarding preferences using decisions in the role of secondmover in the sequential prisoner's dilemma game described in Section 2. The use of the strategy method allows us to observe two decisions from each participant in the role of second-mover: one for the case where the first-mover behaves uncooperatively and sends $\$ 0$, and one for the case where the first-mover is cooperative and sends $\$ 5$. This allows us to classify subjects into three well-defined "pure" types depending on how cooperatively they respond to the firstmover's actions. ${ }^{9}$ Subjects who behave uncooperatively and choose the payoff-maximizing action (return \$0) irrespective of the amount sent by the first-mover are classified as "Free Riders". Subjects who choose the most cooperative action available (send back \$5) if the firstmover sends $\$ 5$, but behave uncooperatively and send back $\$ 0$ otherwise are classified as "Conditional Cooperators". Finally, subjects who always choose the most cooperative action available and send back $\$ 5$ irrespective of what the first-mover sends to them are classified as "Unconditional Cooperators". Note that, while Free Riders do not display other-regarding concerns as they always choose the action that maximizes their own payoff, both Conditional and Unconditional Cooperators exhibit other-regarding concerns as they are willing to forgo material gain to increase the payoff of the opponent.

\footnotetext{
${ }^{8}$ The experiment also delivers data on unconditional cooperation decisions by subjects in the role of first-mover. Compared to decisions as second-mover, it is more difficult to infer other-regarding motives from first-movers' choices since these may also reflect considerations about the profitability of cooperating, false-consensus effects, etc. (see, e.g., (Gächter et al., forthcoming 2011)). For this reason, in the main text we focus on decisions in the role of second-mover, and only briefly discuss here first-mover's behavior. In the role of first-mover, $74 \%$ of Subset 2 , Self-Selected Non-Students, chose to transfer $\$ 5$ to the second-mover. This is significantly more than the fraction of Subset 1, Self-Selected Students, choosing to do so $\left(55 \%, \chi^{2}(1)=6.93, p=0.008\right)$. The share of Subset 3, NonSelf-Selected Non-Students, sending $\$ 5$ is $67 \%$, which is not significantly different from that of Subset 2, SelfSelected Non-Students $\left(\chi^{2}(1)=1.38, p=0.239\right)$. Further analysis of the first mover behavior of Subset 3 may be found in Burks et al. (2009b)

${ }^{9}$ In order to have a well-defined classification of subjects' cooperativeness one needs to observe their behavior in both subgames. Observing second-movers' behavior in only one subgame may not be sufficient. For example, observing a second-mover who sends $\$ 0$ when the first-mover sends $\$ 0$ does not reveal whether she is a 'conditional cooperator' who defects when the first-mover defects, or whether she is instead motivated by material payoff maximization. The use of the strategy method solves this problem by allowing us to observe how a second-mover responds to both possible decisions of the first-mover.
} 
This approach allows us to classify $61 \%$ of the Students, $53 \%$ of the Self-Selected NonStudents, and $62 \%$ of the Non-Self-Selected Non-Students. To assign the remaining participants to a type category we calculate, for each subject, the Euclidean distance between his or her decisions and the decisions that each of the three "pure" types would make, and then assign the subject to the least distant type category. ${ }^{10}$ We can thus classify all but 25 subjects ( 2 in Subset 1 , Self-Selected Students, and 23 in Subset 3, Non-Self-Selected Non-Students): these participants are classified separately as "Others". ${ }^{11}$ Figure 1 shows the distribution of types across the different subject pools.

\section{Figure 1: Distribution of Other-Regarding Preferences across Subject Pools}
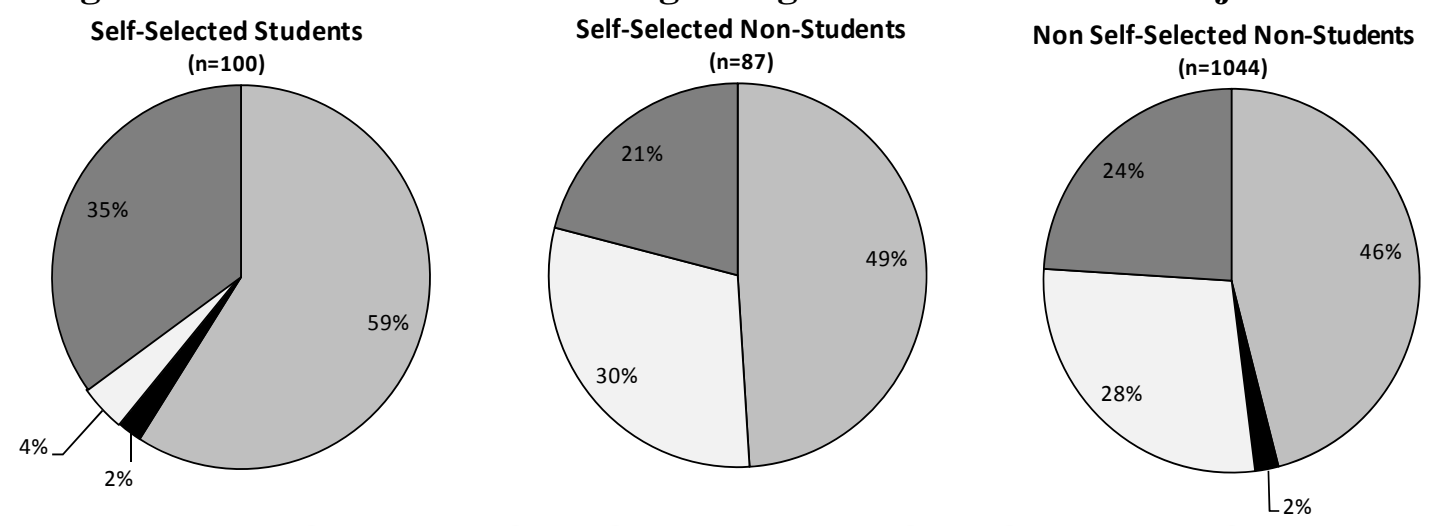

Free Riders $\square$ Conditional Coop. $\quad \square$ Unconditional Coop.

A first notable feature of Figure 1 is the similarity between the distributions of cooperation types across the two non-student subject pools. The shares of subjects that we classify as Free Riders, Conditional Cooperators and Unconditional Cooperators are remarkably similar across non-student participants who self-selected into the experiment and those who did not self-select into the experiment. In fact, a comparison between these two groups reveals that the distribution of types does not differ significantly $\left(\chi^{2}(2)=0.61, p=0.737\right)$. Thus, measurements based on

\footnotetext{
${ }^{10}$ Formally, if $x_{\$ 0}$ is the amount that a subject returns when the first-mover sends $\$ 0$ and $x_{\$ 5}$ is the amount returned when the first-mover sends $\$ 5$, we compute the distance of the subject's decisions from the pure Free Rider type as $D_{F R}=\sqrt{\left(x_{\$ 0}-0\right)^{2}+\left(x_{\$ 5}-0\right)^{2}}$, from the pure Conditional Cooperator type as $D_{C C}=\sqrt{\left(x_{\$ 0}-0\right)^{2}+\left(x_{\$ 5}-5\right)^{2}}$, and from the pure Unconditional Cooperator type as $D_{U C}=\sqrt{\left(x_{\$ 0}-5\right)^{2}+\left(x_{\$ 5}-5\right)^{2}}$.

${ }^{11}$ All participants classified as Others cannot be classified because they are equally distant from a pure Free Rider and a pure Unconditional Cooperator. In the remainder of this sub-section we will focus on the three major cooperation types and ignore the 25 subjects classified as Others.
} 
samples of non-student volunteers who self-select into the experimental environments do not seem to overestimate the prevalence of other-regarding preferences. ${ }^{12}$

A second feature that emerges from Figure 1 is that the share of individuals exhibiting other-regarding concerns is clearly smaller among Subset 1, Self-Selected Students than among Subset 2, Self-Selected Non-Students. The share of students who display some form of otherregarding behavior is $63 \%$, while $79 \%$ of the non-students are classified either as a Conditional Cooperator or as an Unconditional Cooperator. In fact, we can reject the hypothesis that the two groups are sampled from the same population at the $1 \%$ level $\left(\chi^{2}(2)=23.52, p<0.001\right)$.

We further examine the distributions of types across subject pools using regression analysis that allows us to control for observable differences across groups. We use a multinomial logit regression model where the dependent variable is a categorical variable describing whether a subject is classified as a Free Rider, a Conditional Cooperator or an Unconditional Cooperator. In Model I we only use dummy variables for the different subject pools as regressors (note that the reference category is Subset 2, the group of Self-Selected Non-Students). Model II expands Model I by adding the set of controls for socio-demographic characteristics listed in Table 2: age, gender, years of education, number of siblings, dummy variables describing the subject's marital status and the marital status of the subject's parents, a dummy variable for racial characteristics, and a set of dummy variables for different income categories. To allow for potential nonlinearities we also include quadratic terms of the continuous explanatory variables (age, years of education, and number of siblings). The regression results are reported in Table $3 .{ }^{13}$

\footnotetext{
${ }^{12}$ This is the case even when we correct for the $9.2 \%$ attrition rate in the Non Self-Selected Non-Student sample. Assuming the extreme case that the 109 trainees who did not participate are uniformly those who are least otherregarding and who would then be classified as Free Riders, we would still fail to reject the null hypothesis that the distribution of other-regarding preferences types does not differ between the non-student groups $\left(\chi^{2}(2)=\right.$ $4.586, p=0.101)$.

${ }^{13}$ The multinomial logit model relies on the assumption known as the 'independence of irrelevant alternatives' (IIA) whereby introducing or removing any category type from our classification should have the same proportional impact on the probability of the other categories. We tested the IIA assumption using the two tests presented by Long and Freese (2006), the Hausman test and the Small-Hsiao test. The results suggest that the IIA assumption has not been violated (these tests results are available from the authors upon request).
} 
Table 3: Other-Regarding Preferences \& Subject Pools (Percentage Change in the Odds Ratios)

\begin{tabular}{|c|c|c|c|c|c|c|}
\hline & \multicolumn{2}{|c|}{$\begin{array}{l}\text { Cond. Coop. vs. } \\
\text { Free Rider }\end{array}$} & \multicolumn{2}{|c|}{$\begin{array}{l}\text { Uncond. Coop. vs. } \\
\quad \text { Free Rider }\end{array}$} & \multicolumn{2}{|c|}{$\begin{array}{l}\text { Uncond. Coop. vs. } \\
\text { Cond. Coop. }\end{array}$} \\
\hline & $I a$ & II & $I b$ & $I I b$ & Ic & IIc \\
\hline Subset 1, Self-Selected Students & $\begin{array}{l}-29.4 \\
(.323)\end{array}$ & $\begin{array}{l}-33.1 \\
(.354)\end{array}$ & $\begin{array}{l}-92.1^{* * *} \\
(.000)\end{array}$ & $\begin{array}{c}-84.5^{* * *} \\
(.006)\end{array}$ & $\begin{array}{c}-88.8^{* * *} \\
(.000)\end{array}$ & $\begin{array}{l}-76.8^{* *} \\
(.022)\end{array}$ \\
\hline $\begin{array}{l}\text { Subset 3, Non-Self-Selected Non- } \\
\text { Students }\end{array}$ & $\begin{array}{l}-20.0 \\
(.445)\end{array}$ & $\begin{array}{l}15.0 \\
(.675)\end{array}$ & $\begin{array}{l}-17.7 \\
(.541)\end{array}$ & $\begin{array}{c}4.7 \\
(.901)\end{array}$ & $\begin{array}{l}2.8 \\
(.914)\end{array}$ & $\begin{array}{l}-9.0 \\
(.762)\end{array}$ \\
\hline Age & - & $\begin{array}{l}-5.9 \\
(.520)\end{array}$ & - & $\begin{array}{l}41.2^{* * *} \\
(.001)\end{array}$ & - & $\begin{array}{l}50.1^{* * *} \\
(.000)\end{array}$ \\
\hline $\operatorname{Age}^{2} / 100$ & - & $\begin{array}{l}3.7 \\
(.705)\end{array}$ & - & $\begin{array}{c}-1.2 \\
(.909)\end{array}$ & - & $\begin{array}{l}-4.7 \\
(.543)\end{array}$ \\
\hline Gender ( 1 if Female) & - & $\begin{array}{l}-16.2 \\
(.399)\end{array}$ & - & $\begin{array}{l}-21.4 \\
(.342)\end{array}$ & - & $\begin{array}{l}-6.3 \\
(.778)\end{array}$ \\
\hline Non - White or Hispanic & - & $\begin{array}{l}-14.0 \\
(.413)\end{array}$ & - & $\begin{array}{l}-17.4 \\
(.383)\end{array}$ & - & $\begin{array}{l}-4.0 \\
(.834)\end{array}$ \\
\hline Number of Siblings & - & $\begin{array}{l}-6.8 \\
(.437)\end{array}$ & - & $\begin{array}{c}6.6 \\
(.541)\end{array}$ & - & $\begin{array}{l}14.4 \\
(.148)\end{array}$ \\
\hline Number of Siblings ${ }^{2} / 100$ & - & $\begin{array}{l}-5.0 \\
(.565)\end{array}$ & - & $\begin{array}{l}-4.9 \\
(.619)\end{array}$ & - & $\begin{array}{l}0.0 \\
(.996)\end{array}$ \\
\hline Years of Education Completed & - & $\begin{array}{l}35.8^{* * *} \\
(.001)\end{array}$ & - & $\begin{array}{l}3.9 \\
(.697)\end{array}$ & - & $\begin{array}{l}-23.5^{* * *} \\
(.001)\end{array}$ \\
\hline Years of Education Completed ${ }^{2} / 100$ & - & $\begin{array}{c}9.0 \\
(.292)\end{array}$ & - & $\begin{array}{l}3.0 \\
(.727)\end{array}$ & - & $\begin{array}{l}-5.5 \\
(.436)\end{array}$ \\
\hline Marital Status (1 if Single/etc.) & - & $\begin{array}{l}-19.9 \\
(.175)\end{array}$ & - & $\begin{array}{l}-4.8 \\
(.783)\end{array}$ & - & $\begin{array}{l}18.8 \\
(.270)\end{array}$ \\
\hline $\begin{array}{l}\text { Marital Status of Parents ( } 1 \text { if } \\
\text { Single/etc.) }\end{array}$ & - & $\begin{array}{l}-5.5 \\
(.730)\end{array}$ & - & $\begin{array}{l}19.5 \\
(.331)\end{array}$ & - & $\begin{array}{l}26.5 \\
(.137)\end{array}$ \\
\hline \multicolumn{7}{|l|}{ Income Category } \\
\hline$\$ 10,000-\$ 20,000$ & - & $\begin{array}{l}-0.3 \\
(.988)\end{array}$ & - & $\begin{array}{l}33.8 \\
(.271)\end{array}$ & - & $\begin{array}{l}34.3 \\
(.191)\end{array}$ \\
\hline$\$ 20,000-\$ 30,000$ & - & $\begin{array}{l}-34.4^{*} \\
(.061)\end{array}$ & - & $\begin{array}{l}-12.9 \\
(.583)\end{array}$ & - & $\begin{array}{l}32.9 \\
(.222)\end{array}$ \\
\hline$\$ 30,000-\$ 40,000$ & - & $\begin{array}{l}-19.2 \\
(.423)\end{array}$ & - & $\begin{array}{c}32.2 \\
(.326)\end{array}$ & - & $\begin{array}{l}63.6^{* *} \\
(.050)\end{array}$ \\
\hline$\$ 40,000-\$ 50,000$ & - & $\begin{array}{l}84.5^{*} \\
(.053)\end{array}$ & - & $\begin{array}{c}119.2^{* *} \\
(.025)\end{array}$ & - & $\begin{array}{l}18.8 \\
(.530)\end{array}$ \\
\hline$\$ 50,000-\$ 60,000$ & - & $\begin{array}{l}-4.4 \\
(.899)\end{array}$ & - & $\begin{array}{l}31.7 \\
(.473)\end{array}$ & - & $\begin{array}{l}37.8 \\
(.311)\end{array}$ \\
\hline$\$ 60,000-\$ 70,000$ & - & $\begin{array}{l}21.6 \\
(.620)\end{array}$ & - & $\begin{array}{c}166.4^{* *} \\
(.023)\end{array}$ & - & $\begin{array}{l}119.0^{* * *} \\
(.028)\end{array}$ \\
\hline$\$ 70,000+$ & - & $\begin{array}{c}21.2 \\
(.521)\end{array}$ & - & $\begin{array}{c}8.4 \\
(.841)\end{array}$ & - & $\begin{array}{l}-10.5 \\
(.755)\end{array}$ \\
\hline$N$. & 1206 & 1206 & 1206 & 1206 & 1206 & 1206 \\
\hline Wald $\chi^{2}$ & 20.36 & 95.89 & 20.36 & 95.89 & 20.36 & 95.89 \\
\hline Prob $>\chi^{2}$ & 0.000 & 0.000 & 0.000 & 0.000 & 0.000 & 0.000 \\
\hline Pseudo $R^{2}$ & 0.016 & 0.047 & 0.016 & 0.047 & 0.016 & 0.047 \\
\hline
\end{tabular}

Multinomial logit regression with robust standard errors. Dependent variable is subject's preference type: whether a subject is classified as type $m$ (listed first in the column heading) rather than type $n$ (listed second in the column heading). Results are reported as percentage changes in the odds ratios, which multiply the odds ratio of the reference subject type, which is: Self-Selected Non-Student, Male, Married, Adult, with Married Parents, White (Non-Hispanic), Income category $\$ 0-\$ 10,000$. Dummy variables are treated in the standard manner. For continuous variables (Age, Years of Education Completed, Number of Siblings and their quadratic terms) the Table reports changes after a standard deviation increase in the explanatory variable (standard deviations are: 11.5 for Age, 1.42 for Age $2 / 100,1.69$ for Years of Education Completed, 0.06 for Years of Education Completed $2 / 100,1.96$ for Number of Siblings, 0.07 for Number of Siblings $2 / 100$ ). Continuous variables are centered at their mean (means are: 36.2 for Age, 13.2 for Years of Education Completed, and 2.8 for Number of Siblings), and quadratic terms are computed for the mean-centered variables. P-values are reported in parentheses. A constant is included in all models, but omitted from the Table output. Significance levels: * $10 \% ; * * 5 \% ; * * * 1 \%$. 
Starting with the equations of Model I, we confirm that the distribution of types across non-student subject pools is not affected by whether participants did or did not self-select into the experiment. The odds of being classified as a Free Rider, a Conditional Cooperator, or an Unconditional Cooperator are not different between the two subject pools at any conventional significance level. These results hold also in Model II where we add controls for sociodemographic characteristics.

Model I also confirms that Self-Selected Students (Subset 1) are significantly less likely to engage in one specific form of other-regarding behavior as compared to the regression reference group, Self-Selected Non-Students (Subset 2). Equations Ib and Ic show that Self-Selected Students have substantially lower odds of being classified as Unconditional Cooperators. The odds of being an Unconditional Cooperator rather than a Free Rider are $92 \%$ lower for a student than for a Self-Selected Non-Student. Similarly, being a student decreases by about $89 \%$ the odds of being classified as an Unconditional Cooperator rather than a Conditional Cooperator. The effects are significant at the $1 \%$ level for both equations in Model I, and remain statistically significant in Model II after controlling for observable differences between subject pools (at the $1 \%$ level for equation IIb, at the $5 \%$ level for equation IIc). When we consider the second type of other-regarding behavior that is possible in our experiment, we find that Self-Selected Students (Subset 1) are not significantly less likely than the regression reference group, Self-Selected NonStudents (Subset 2), to be classified as a Conditional Cooperator rather than a Free Rider (see equations Ia and IIa).

Among the controls for socio-demographic characteristics included in Model II, age has a positive impact on the odds of being classified as an Unconditional Cooperator (see equations IIb and IIc). This finding is in line with results from other studies showing that older people tend to be more cooperative than younger people (e.g., (Carpenter et al., 2005; List, 2004)). Interestingly, having more years of education appears to increase the odds of being classified as a Conditional Cooperator relative to any of the other two type categories (see equations IIa and IIc). In both equations the effects are significant at the $1 \%$ level.

\subsection{Need for social approval across subject pools}

Overall, our results on behavior in the social dilemma game suggest that volunteers who self-select into economic experiments and those who do not self-select do not differ significantly in their other-regarding inclinations. Research from social psychology, however, suggests that a 
dimension in which self-selected and non-self-selected volunteers might also differ is in their need for social approval (see, e.g., Rosenthal and Rosnow (1969)). Approval-seeking participants may be systematically more prone to cooperate with the experimenter (e.g. by behaving in accordance with the perceived experimental objectives, or with what is perceived to constitute "appropriate" behavior), and this may also distort measurements collected through experiments.

To examine whether the need for social approval is higher among participants who selfselect into the experiment than among non-self-selected participants Table 4 shows, disaggregated by subject pool, participants' scores in the Unlikely Virtues Scale, a stand-alone index of social desirability with higher scores indicating more socially desirable responding. ${ }^{14}$

Table 4: Unlikely Virtues Scale \& Subject Pools

\begin{tabular}{l|ccc}
\hline \hline & $\begin{array}{c}\text { Subset 1 } \\
\text { Self-Selected } \\
\text { Students } \\
(\mathrm{n}=100)\end{array}$ & $\begin{array}{c}\text { Subset 2 } \\
\text { Self-Selected } \\
\text { Non-Students } \\
(\mathrm{n}=87)\end{array}$ & $\begin{array}{c}\text { Subset 3 } \\
\text { Non-Self-Selected } \\
\text { Non-Students } \\
(\mathrm{n}=1044)\end{array}$ \\
\hline Mean & 29.8 & 33.6 & 34.3 \\
Standard Deviation & 4.05 & 3.35 & 4.32 \\
Min. - Max. & $18-43$ & $25-42$ & $21-52$ \\
\hline \hline
\end{tabular}

Table 4 reveals that self-selected participants did not respond in a more socially desirable manner to the Unlikely Virtues Scale questions than participants who did not self-select into the experiment. In fact, the group of Non-Students who did not self-select into the experiment scored highest in the Unlikely Virtues Scale. A two-sided Mann-Whitney-U-test shows that the difference between Subset 2, Self-Selected and Subset 3, Non-Self-Selected Non-Students approaches statistical significance $(p=0.102)$. Table 4 also shows that Subset 1 , Students' scores are much lower than the scores of Subset 2, Self-Selected Non-Students. A two-sided Mann-Whitney-U-test reveals that the difference is statistically significant $(p<0.001){ }^{15}$

A Tobit regression controlling for subjects' socio-demographic characteristics confirms both results. The regression estimates show that, ceteris paribus, Subset 3, Non-Self-Selected Non-Students score about 1 point higher than Subset 2, Self-Selected Non-Students in the

\footnotetext{
${ }^{14}$ For 29 Non Self-Selected Non-Students there are missing data for some of the items composing the Unlikely Virtues Scale. To compute a score for these subjects we impute the neutral midpoint of the scale for those items whose answers are missing. Results do not change if we conduct the analysis excluding these 29 subjects.

${ }^{15}$ Although it is standard to simply sum the responses to summarize the Unlikely Virtues Scale, we also conducted a factor analysis. The analysis resulted in one eigenvalue above one and using the resulting factor scores we find similar results: two-sided Mann-Whitney-U-tests reveal that socially desirable responding is somewhat more prevalent in Subset 3 than in Subset $2(p=0.094)$, and much more prevalent in Subset 2 than in Subset 1(p=0.000) .
} 
Unlikely Virtues Scale, and the difference is statistically significant $(p=0.050)$. On the other hand, Subset 1, Students on average score about 2.89 points lower than Self-Selected NonStudents, and the difference is highly significant $(p=0.000){ }^{16}$

\section{Discussion \& Conclusions}

Several studies have shown that other-regarding preferences are an important behavioral motivation for a large fraction of participants in economic experiments. However, because in most of these studies participants were undergraduate students who self-selected into the experimental environments, it is an open question whether and to what extent these findings can be generalized to different populations and settings. Generalizations from studies using selfselected student samples may be problematic for two reasons. First, there could be a positive correlation between volunteering to participate in experimental studies and the extent to which participants are likely to engage in other-regarding behaviors during an experiment. Second, undergraduate students could differ from the more general population in the extent to which they are motivated by other-regarding considerations, as they differ in a number of other important social, economic and demographic dimensions.

In this study we address these concerns by measuring and comparing the preferences of samples from three different subject pools from the upper Midwest of the United States: Subset 1, a subject pool of self-selected undergraduate students (from the University of Minnesota, Morris), Subset 2, a subject pool of self-selected non-students (non-student adults from the Morris area), and Subset 3, a subject pool of non-self-selected non-students (trainee truckers undertaking a two-week residential training program in Wisconsin). To measure other-regarding preferences we use a sequential prisoner's dilemma game experiment that allows us to classify subjects in three categories based on their conditional cooperativeness: Free Riders, Conditional Cooperators, and Unconditional Cooperators.

With regards to the self-selection issue, we do not find any significant difference in the distribution of other-regarding preferences across our two non-student subject pools, which differ in the extent to which participants were able to self-select into the study. We also do not find significant differences between the two non-student groups in the extent to which they engage in

\footnotetext{
${ }^{16}$ The regression also shows that approval-seeking is positively correlated with age $(\mathrm{p}=0.001)$ and with the dummy variable for Non-White or Hispanic subjects $(\mathrm{p}=0.000)$. Full regressions results are available upon request.
}

Page 16 of 26 
socially desirable responding as measured by the Unlikely Virtues Scale. ${ }^{17}$ Overall, these findings suggest that it is unlikely that the use of self-selected samples leads to systematic distortions in the measurement of other-regarding preferences.

Only a few studies have investigated empirically the possibility that more pro-socially inclined individuals self-select into economic experiments. Eckel and Grossman (2000) use a dictator game to compare the behavior of "volunteers" (students recruited through prior announcements in graduate and undergraduate classes) and "pseudo-volunteers" (students recruited from a class to immediately participate in the experiment during class time in order to minimize potential self-selection issues). They find that volunteers are significantly less generous than pseudo-volunteers and that they behave in a less extreme manner, suggesting that they are more motivated by monetary incentives. However, as also noted by Eckel and Grossman, these differences may reflect the fact that pseudo-volunteers were exposed to a more authoritative environment, which could have amplified potential experimenter demand effects (see also Zizzo (2010)). These concerns are minimized in our setting, since there was no close relation between the non-self-selected participants and the experimenters conducting the study, and the informedconsent process emphasized the strict confidentiality of individual data including specifically that it would never be available to their managers at the trucking firm.

In a recent study, Cleave et al. (2010) recruited 1,173 students into experiments carried out during class time in order to minimize self-selection, and measured their other-regarding preferences using a trust game. They later invited the 1,173 students to take part in a subsequent laboratory experiment, and examine whether those who decided to eventually participate in the experiment had different preferences than the original population. They do not find a selection bias based on other-regarding preferences. Finally, Falk et al. (2010) have examined whether students' decisions to take part in economic experiments organized by the experimental economics laboratory at the University of Zurich are related to their pro-social inclinations as measured by their contributions to two charitable funds providing financial support to foreign and needy students to which all students must decide about donating. They find that students who take part in experiments are not more pro-social than non-participant students. Our results complement the findings from these studies with students, and show that also among non-student samples, self-selection effects with respect to other-regarding preferences are negligible.

\footnotetext{
${ }^{17}$ Nor do they differ in in subjects' cooperativeness in the role of first-mover in the prisoner's dilemma experiment.
} 
Turning to the comparison between students and non-students, we find that the share of subjects who are motivated by other-regarding considerations is remarkably smaller among students. In particular, we find that the share of Unconditional Cooperators is smaller among students (4\%) than among non-students (30\%). In fact, students are significantly less likely than non-students to be classified as Unconditional Cooperators even after controlling for differences in the socio-demographic characteristics of participants. ${ }^{18}$ Overall, these results suggest that generalizations about the pervasiveness of other-regarding motives from measurements conducted using undergraduate students may understate the behavioral relevance of otherregarding preferences (see also Henrich et al., 2010).

Our results are in line with findings from several other studies that have compared undergraduate student samples with non-student samples and find less pro-sociality among the former (Bellemare and Kroger, 2007; Carpenter et al., 2008; Falk et al., 2010; Fehr and List, 2004; Hoffman and Morgan, 2010). In particular, in the context of voluntary cooperation both Stoop and Noussair (2009) and Carpenter and Seki (2010) find that students are significantly less cooperative than fishermen in voluntary contribution mechanism experiments. ${ }^{19}$ In the context of bargaining games our findings are also in line with results reported by Carpenter et al. (2005) who study student and non-student (warehouse worker) samples using ultimatum game and dictator games. They observe the usual result that among students there is a large fraction of high offers in the ultimatum game (UG) which drops to a low fraction in the dictator game (DG), but find that almost all non-students make high offers in both games. This difference in DG giving is analogous to the present results about the difference between students and non-students in the proportion of Unconditional Cooperators.

Most closely related to our study, Burks et al. (2009a) use a sequential prisoner's dilemma game to compare undergraduate students in Zürich to bicycle messengers in Zürich and San Francisco, and find that the latter are significantly more cooperative than the former. In particular, they also classify subjects according to their (conditional) cooperativeness and find

\footnotetext{
${ }^{18}$ In addition, the share of Free Riders is higher among students (35\%) than among non-students (24\%).

${ }^{19}$ Gächter et al. (2004) also find that students contribute less than non-students to a public good, although differences between subject pools vanish once socio-economic background characteristics of participants are accounted for.
} 
that there are far fewer Unconditional Cooperators and far more Free Riders among students than among messengers. ${ }^{20}$

Taken together, the findings from our study and the related literature suggest that measurements of other-regarding preferences based on self-selected samples are not systematically biased upwards. The pro-social inclinations of subjects who self-selected into the experiments are not significantly different from the inclinations of those who had instead very little opportunity to self-select into the study.

Further, a common picture emerging from a significant collection of experimental studies, including ours, is that the use of student samples may lead to underestimating the pervasiveness of other-regarding preferences. There now appears to be substantial accumulated evidence suggesting that measurements obtained from undergraduate students represent a lower bound on the extent to which the more general population of advanced industrial societies exhibits otherregarding behaviors in behavioral economic laboratory experiments. ${ }^{21}$

\footnotetext{
${ }^{20}$ Burks et al. (2009a) label Unconditional Cooperators "Altruists" and Free Riders "Egoists."

${ }^{21}$ Where the populations of advanced industrial societies fall in the full range of behavior typical of humans as a species is an open question that our data do not address; see, for example, the discussion in Henrich et al. (2010).
} 


\section{APPENDIX A: INSTRUCTION SCRIPT FOR THE SOCIAL DILEMMA EXPERIMENT}

What follows is the text of the script spoken by Burks to each group of subjects. Subjects also saw an abbreviated version of these instructions on their computer screens, while they were listening to the instructions. The table mentioned in this text is in Appendix B.

\section{ACTIVITy ONE: TWO-PERSON SENDING DeCISION.}

This activity does not take very long to do, but it is the most complicated thing to explain that we will do all day. So please bear with me as I give you the details.

You are going to make the decisions in this task ONCE. Some things you do today are going to be repeated, but the decisions in this task are not among the things we will repeat.

The BASICS OF THIS ACTIVITY ARE VERY SIMPLE, and so let me start there.

In this activity there are two different roles, Person 1 and Person 2. When we figure out your payoff you will be either a Person 1, or a Person 2, but not both. Each Person 1 will be matched with a Person 2 here in this room, but neither of you will ever know which specific other driver trainee you have been matched with.

Whether you are a Person 1 or a Person 2, the basics are the same. You will have a new amount of five dollars put in your account at the beginning of this activity by us. You have to decide whether to keep this five dollars, or to send it to the other person you are paired with. If you KEEP the money, it is yours at the end of the activity. If you SEND the money, we will double it, so that the person you send it to gets twice what you sent. Likewise, the person you are matched with will be making a SIMILAR decision about their five dollars. If they keep it, then it is theirs at the end of the activity, but if they send it to you, you will get twice what they sent.

So, that is the basic OutLine. NeXT We WiLl LOOK At the Details.

If you are a Person 1 your decision is simple. You have to decide whether to send your five dollars to Person 2, or to keep it. If you keep it, it is yours at the end of the activity, but if you send it to Person 2, we will double it, so that Person 2 actually gets $\$ 10$.

Now, Person 2 also gets to decide about sending money to Person 1. But there are a couple of special features to Person 2's decision.

The first special feature is that Person 2 doesn't just have a yes-no choice about sending the five dollars. Instead, Person 2 can send any exact dollar amount to Person 1. So Person 2 can send: $\$ 0, \$ 1, \$ 2, \$ 3, \$ 4$, or $\$ 5$. Just like before, however, whatever Person 2 keeps is theirs at the end of the activity, and whatever Person 2 sends will be doubled by the researchers.

Example: if Person 2 keeps $\$ 4$ and sends $\$ 1$ to Person 1, Person 1 will actually receive $\$ 2$, Example: if Person 2 keeps $\$ 2$ and sends $\$ 3$ to Person 1, Person 1 will actually receive $\$ 6$. 
The second special feature is that Person 2 gets to decide what to do under two different cases. The first case is how much they want to respond if Person 1 has not sent them money. This choice will be on the LEFT side of the Person 2 choice screen. The second case is how much they want to respond if Person 1 has sent them money. This choice will be on the RIGHT side of the Person 2 choice screen. In both cases the rules are the same: Person 2 can choose how many dollars to keep and how many to send, and whatever is sent is doubled.

TABLE OF PAYOFFS IS HANDED OUT. (table is provided following end of script text)

PLEASE DO NOT WRITE ON THIS SHEET, AS WE WILL RE-USE IT.

Look at payoff handout sheet.

Let's look at the top table. As you can see from looking at the first column (from Line 1 to Line 6 ), the top table is for the case in which Person 1 decides to send Person $2 \underline{\$ 0}$. If you look at the second column of the top table (from Line 1 to Line 6), you can see all of the possible choices Person 2 has about how to respond. Finally, in each line, if you follow the arrow to the right, you see two more columns that show what the two people, Person 1 and Person 2, make in earnings. So, Lines 1 through 6 show each response Person 2 can make to the decision of Person 1 to send $\$ 0$, and the payoffs each of them receive.

Example: look at Line 1. From the first two columns, this is the situation in which Person 1 sends $\$ 0$, and Person 2 responds by also sending back $\$ 0$. Following the arrow to the right, you can see that Person 1 makes $\$ 5$, because he keeps $\$ 5$, and gets $\$ 0$ from Person 2, and Person 2 also makes $\$ 5$, because he keeps all of his initial $\$ 5$, and also receives nothing from Person 1 .

Example: look at Line 4. From the first two columns, this is the situation in which Person 1 sends $\$ 0$, and Person 2 responds by sending back $\$ 3$. Following the arrow to the right, you can see that Person 1 makes $\$ 11$, because he keeps $\$ 5$, and also gets $\$ 3$ doubled to $\$ 6$ from Person 2 . But Person 2 makes $\$ 2$, because he sent $\$ 3$ of his initial $\$ 5$, but received nothing back.

Example: look at Line 6. From the first two columns, this is the situation in which Person 1 sends $\$ 0$, and Person 2 responds by sending back $\$ 5$. Following the arrow to the right, you can see that Person 1 makes $\$ 15$, because he keeps $\$ 5$, and also gets $\$ 5$ doubled to $\$ 10$ from Person 2. But Person 2 makes $\$ 0$, because he sent all of his initial $\$ 5$, but received nothing back.

Now let's look at the bottom table. This repeats the same pattern as the top table, except that, as you can see from looking at the first column (from Line 7 to Line 12), it is for the case in which Person 1 sends $\$ 5$ to Person 2. If you look at the second column of the bottom table (from Line 7 to Line 12), you can see all of the possible choices Person 2 has about how to respond. Finally, in each line, if you follow the arrow to the right, you see two more columns that show what the two people, Person 1 and Person 2, make in earnings. So, Lines 7 through 12 show each response Person 2 can make to the decision of Person 1 to send \$5, and the payoffs each of them receive.

Example: look at Line 7. From the first two columns, this is the situation in which Person 1 sends $\$ 5$, and Person 2 responds by sending back $\$ 0$. Following the arrow to the right, you can see that Person 1 makes $\$ 0$, because he sent all his initial $\$ 5$, and gets $\$ 0$ back from Person 2, but

Page 21 of 26 
Person 2 makes $\$ 15$, because he keeps all of his initial $\$ 5$, and also gets $\$ 5$ doubled to $\$ 10$ from Person 1.

Example: look at Line 9. From the first two columns, this is the situation in which Person 1 sends $\$ 5$, and Person 2 responds by sending back $\$ 2$. Following the arrow to the right, you can see that Person 1 makes $\$ 4$, because he sent all of his initial $\$ 5$, and gets $\$ 2$ doubled to $\$ 4$ back from Person 2. And Person 2 makes $\$ 13$, because he kept $\$ 3$ of his initial $\$ 5$, also gets $\$ 5$ doubled to $\$ 10$ from Person 1

Example: look at Line 12. From the first two columns, this is the situation in which Person 1 sends $\$ 5$, and Person 2 responds by sending back $\$ 5$. Following the arrow to the right, you can see that Person 1 makes $\$ 10$, because he sent all his $\$ 5$, and gets back $\$ 5$ doubled to $\$ 10$ from Person 2. And Person 2 also makes $\$ 10$, because he sent back all of his initial $\$ 5$, also got $\$ 5$ doubled to $\$ 10$ from Person 1 .

Any questions now?

OK, now for the next to last special feature. This is very important. We are going to randomly assign the roles of Person 1 and Person 2 at the end of the activity, not at the beginning. So, we are going to ask everyone to make a decision first as a Person 1, and then second, a decision as a Person 2.

Let me repeat that: you will first make a decision IN CASE YOU ARE A Person 1, whether you will send $\$ 5$ or not. Then, on a new screen, you will also make a two-decision IN CASE YOU ARE A Person 2: how much to send back if you got \$0 (LEFT SIDE of the screen), and how much to send back if you got $\$ 5$ (doubled to \$10) (RIGHT SIDE of the screen).

So the way the payoffs will work is that first you will be matched by the computer with someone else here in the room. For example, \#11 over here might be matched with \#23 over there. Of course, let me remind you that we will never tell you with whom you were matched. Since everyone made both a Person 1 choice and then a Person 2 choice, once you have been matched, the computer will in effect flip a coin - it will randomly make one of you Person 1 and the other Person 2. Then it will look at your choices and those of the person you were matched with, and calculate your payoffs.

Finally, here is the last special feature. Before each decision screen there is another question. We are not only going to ask you what you want to do, I'd like to know what you think everyone else here today will do. So, we will also ask you to guess how others will handle the decisions you are about to make.

So for instance, right before the Person 1 screen asks you whether you will send $\$ 5$ to Person 2 or not, we will also ask you to guess what percent of the people here in the room will send $\$ 5$ as Person 1 . We will pay you $\$ 1$ extra if your guess is close $(+/-5 \%)$ to what people actually do.

And, when you make your decision as Person 2, you will have to tell us how much you want to send to Person 1 both when Person 1 sent $\$ 0$ to you, and also when Person 1 sent $\$ 5$ to you. 
Right before you make this decision, we will also ask you the average amount in dollars you think people in this room will send in each of these cases. We will pay you $\$ 1$ extra for each guess that is close $(+/-\$ .25)$ to what people actually choose.

So, to recap, you will have FOUR different screens of choices. FIRST, your best guess about the $\%$ of those here today who will send $\$ 5$ as Person 1 . SECOND, your own decision in case the computer makes you a Person 1 for the payoffs. THIRD, your best guess about how much people here will send as Person 2, for the case when they got nothing (LEFT SIDE of the screen), and again for the case in which they received \$5 (RIGHT SIDE of the screen). FOURTH, your own choice in case the computer makes you a Person 2 for the payoffs, of how much to send back to Person 1 when Person 1 sent you $\$ 0$ (LEFT SIDE of the screen), and when Person 1 sent you $\$ 5$ (RIGHT SIDE of the screen).

Any questions now?

At the end of the activity, the computer will show you what your earnings are in total, including both from your guesses about others and from your choices as Person 1 or Person 2.

OK, let's look at the instructions on the first computer screen. When you are happy you understand them, please click "continue" or "OK" in the lower right-hand corner of the screen. That will take you to a waiting screen, and when everyone is there, we will move to the first of two practice question screens, to make sure you understand how the payoff table works.

Practice Screen 1: Person 1 sends $\$ 0$, and Person 2 responds by sending back $\$ 1$. Line 2 (Person 1 gets $\$ 7$, Person 2 gets $\$ 4$ )

Practice Screen 2: Person 1 sends $\$ 5$, and Person 2 responds by sending back $\$ 3$. Line 10 (Person 1 gets $\$ 6$, and Person 2 gets $\$ 12$ ) 


\section{Appendix B: Table of PD Game Payoffs Given to SubJects}

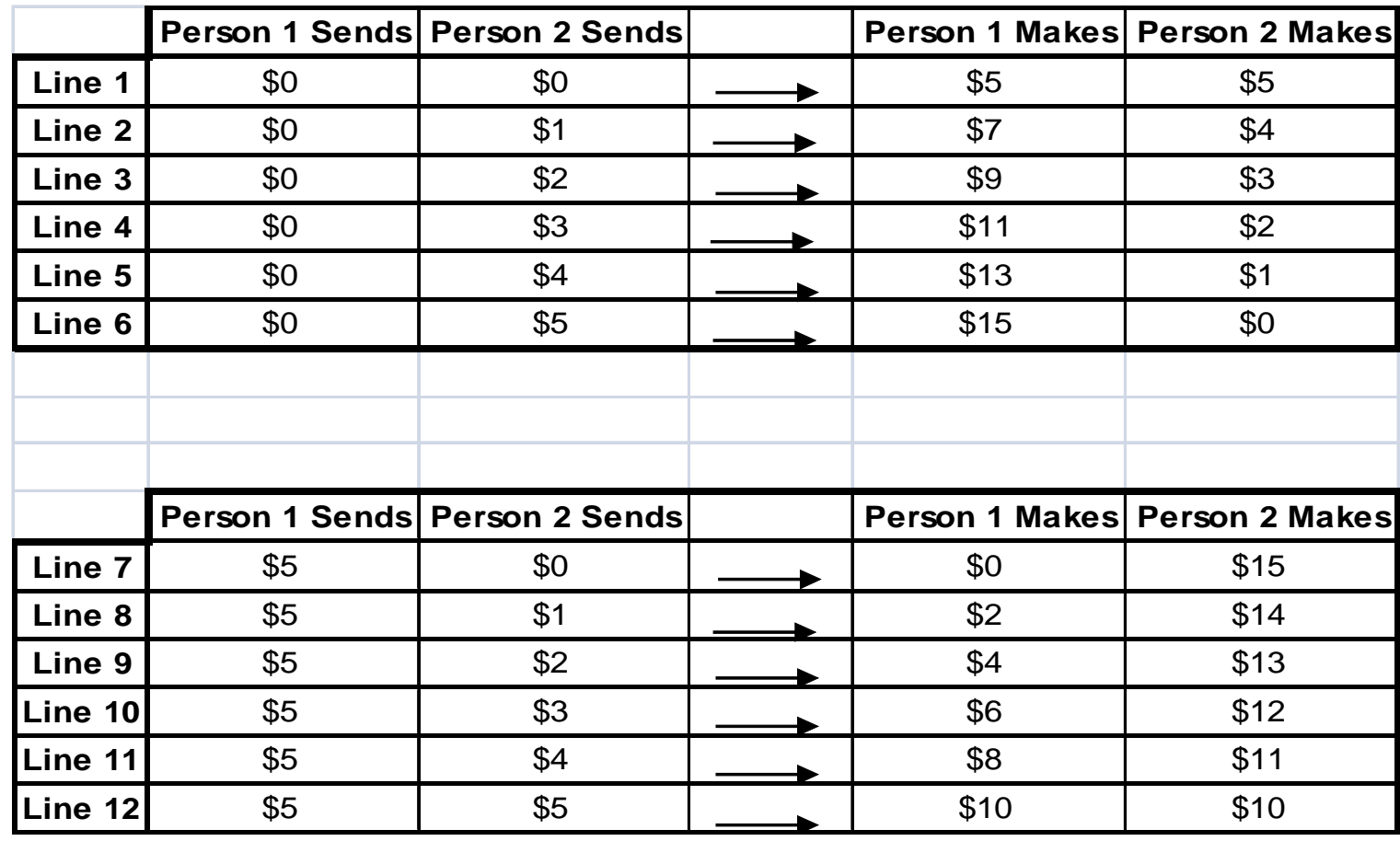




\section{REFERENCES}

Bellemare, C., Kroger, S., 2007. On Representative Social Capital. European Economic Review. 51, 183-202.

Burks, S., et al., 2009a. Performance Pay and Worker Cooperation: Evidence from an Artefactual Field Experiment. Journal of Economic Behavior and Organization. 70, 458469.

Burks, S., et al., Using Behavioral Economic Field Experiments at a Firm: the Context and Design of the Truckers and Turnover Project. In: S. Bender, et al., (Eds.), The Analysis of Firms and Employees: Quantitative and Qualitative Approaches. NBER and University of Chicago Chicago and London, 2008, pp. 45-106.

Burks, S. V., et al., 2009b. Cognitive Skills Affect Economic Preferences, Social Awareness, and Job Attachment. Proceedings of the National Academy of Science (USA). 106, 7745-50.

Camerer, C., 2003. Behavioral Game Theory: Experiments in Strategic Interaction. Princeton University Press, Princeton, NJ.

Carpenter, J., et al., Comparing Students to Workers: the Effects of Social Framing on Behavior in Distribution Games. Research in Experimental Economics, 2005, pp. 261-290.

Carpenter, J., et al., 2008. Altruistic Behavior in a Representative Dictator Experiment. Experimental Economics. 11, 282-298.

Carpenter, J., Seki, E., 2010. Do Social Preferences Increase Productivity? Field Experimental Evidence from Fishermen in Toyama Bay. Economic Inquiry. forthcoming.

Cleave, B. L., et al., Is There Selection Bias in Laboratory Experiments? , Working Paper No. 1106. University of Melbourne Department of Economics, 2010, pp. 1-34.

Eckel, C. C., Grossman, P. J., 2000. Volunteers and Pseudo-volunteers: The Effect of Recruitment Method in Dictator Experiments. Experimental Economics. 3, 107-120.

Falk, A., et al., Did we overestimate the role of social preferences? The case of self-selected student samples. Manuscript, 2010, pp. 1-21.

Fehr, E., List, J. A., 2004. The Hidden Costs and Returns of Incentives--Trust and Trustworthiness among CEOs. Journal of the European Economic Association. 2, 743771.

Fehr, E., Schmidt, K. M., The Economics of Fairness, Reciprocity and Altruism - Experimental Evidence and New Theories. In: S. Kolm, J. M. Ythier, (Eds.), Handbook of the Economics of Giving, Reciprocity and Altruism. Elsevier., 2006, pp. 615-691. .

Fischbacher, U., 2007. Z-Tree: Zurich Toolbox for Ready-Made Economic Experiments. Experimental Economics. 10, 171-178.

Fischbacher, U., et al., 2001. Are People Conditionally Cooperative? Evidence from a Public Goods Experiment. Economics Letters. 71, 397-404.

Gächter, S., et al., 2004. Trust, Voluntary Cooperation, and Socio-economic Background: Survey and Experimental Evidence. Journal of Economic Behavior and Organization. $55,505-531$.

Gächter, S., et al., forthcoming 2011. Who Makes A Good Leader? Cooperativeness, Optimism And Leading-By-Example. Economic Inquiry.

Henrich, J., et al., 2010. The weirdest people in the world? Behavioral and Brain Sciences. 33, 175.

Herrmann, B., Thoni, C., 2009. Measuring Conditional Cooperation: A Replication Study in Russia. Experimental Economics. 12, 87-92. 
Hoffman, M., Morgan, J., Who's Naughty? Who's Nice? Social Preferences in Online Industries. University of California, Berkeley, Manuscript, 2010, pp. http://faculty.haas.berkeley.edu/rjmorgan/NaughtyOrNice.pdf.

Kocher, M. G., et al., 2008. Conditional Cooperation on Three Continents. Economics Letters. 101, 175-178.

Levitt, S. D., List, J. A., 2007. What Do Laboratory Experiments Measuring Social Preferences Reveal about the Real World? Journal of Economic Perspectives. 21, 153-174.

List, J., 2004. Young, Selfish and Male: Field Evidence of Social Preferences. The Economic Journal. 114, 121-149.

Long, S. J., Freese, J., 2006. Regression Models for Categorical Dependent Variables Using Stata. Stata Press, College Station, Texas.

Patrick, C., et al., 2002. Development and Validation of a Brief Form of the Multidimensional Personality Questionnaire. Psychological Assessment. 14, 150-164.

Rosenthal, R., Rosnow, R. L., The Volunteer Subject. In: R. Rosenthal, R. L. Rosnow, (Eds.), Artifact in Behavioral Research. Academic Press, New York and London, 1969, pp. 61118.

Stoop, J., et al., From the lab to the field: Cooperation among fishermen. University of Kiel, Manuscript, 2009, 2 pp. http://www.bwl.unikiel.de/phd/file/Bridge_Stoop_Noussair_vSoest.pdf.

Zizzo, D., 2010. Experimenter demand effects in economic experiments. Experimental Economics. 13, 75-98. 